\title{
STUDY OF VARIATIONS IN THE ORIGIN OF PROFUNDA FEMORIS ARTERY IN ADULT HUMAN CADAVERS
}

\section{U. Sujatha, Prashanti T, K. Chitty Narasamma, Ch. Jayamma.}

${ }^{* 1}$ Assistant professor of Anatomy, Kurnool Medical College, Kurnool, Andhra Pradesh, India.

${ }^{2}$ Assistant Professor of Anatomy, Kurnool Medical College, Kurnool, Andhra Pradesh, India.

${ }^{3}$ Professor and Head in Anatomy, Kurnool Medical College, Kurnool, Andhra Pradesh, India.

${ }^{4}$ Professor of Anatomy, Kurnool Medical College, Kurnool, Andhra Pradesh, India.

\section{ABSTRACT}

Background: Profundafemoris artery is the largest branch of femoral artery and chief supply to all compartments of the thigh. It also supplies head and neck of femur and its branches form anastomosis around head of femur. So the study of variation of profundafemoris artery is of great value for radiologists and surgeons during diagnostic and surgical intervention.

Aims \& objectives: To study the variations in the origin of profundafemoris artery.

Materials and Methods: 25 properly embalmed human cadavers used for routine dissection procedure for undergraduate students in the Department of Anatomy, Kurnool Medical College, Kurnool. Study was done by dissection method as per Cunningham's manual of practical anatomy.

Results: In the present study of profundafemoris artery, we found posterolateral aspect of origin was common than lateral and posteromedial aspect of origin. In one female cadaver, on left side, we noted high origin of profundafemoris artery. On right side of same cadaver, findings were normal.

Conclusion: In the present study, different types of variations like posterolateral and lateral side of origin is noted as common site of origin. Rare variation like posteromedial side origin of profundafemoris artery was observed. Very high level of origin of profundafemoris artery was also observed. Hence the study will help the clinicians to avoid iatrogenic complications and also help them in various clinical procedures and surgeries in femoral region.

KEYWORDS: Profundafemoris artery, Femoral artery, variations.

Address for Correspondence: Dr. U Sujatha, Assistant professor of Anatomy, Kurnool Medical College, Kurnool, Andhra Pradesh, India. Mobile: 9490664433 E-Mail: drusujatha@gmail.com,

Access this Article online

Quick Response code

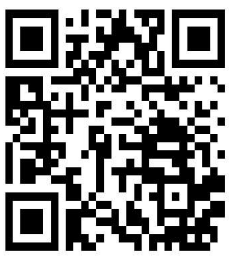

DOI: $10.16965 /$ ijar.2018.439
Journal Information

International Journal of Anatomy and Research

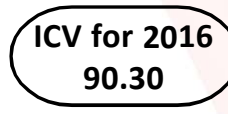

ISSN (E) 2321-4287 | ISSN (P) 2321-8967

https://www.ijmhr.org/ijar.htm

DOI-Prefix: https://dx.doi.org/10.16965/ijar

\section{Article Information}

Received: 07 Dec 2018

Peer Review: 07 Dec 2018

Revised: None
Accepted: 20 Jan 2019

Published (O): 05 Feb 2019

Published (P): 05 Feb 2019

\section{INTRODUCTION}

Profundafemoris artery (PFA) is an important and largest deep branch of femoral artery (FA). It arises posterolaterally from the femoral artery about $3.5 \mathrm{~cm}$ distal to the inguinal ligament. Gives medial and lateral circumflex femoral arteries, muscular and perforating arteries.
Provides chief supply to all compartments of thigh as well as head \& neck of femur and its branches form anastomosis around the head of femur [1].

These vessels are also useful for catheterization in various diagnostic procedures like artereiography, angiography and Doppler imaging techniques. Clinicians call femoral artery (FA) 
as commom femoral artery above the origin of profundafemoris artery (PFA) and superficial femoral artery (SFA) below the origin of PFA [2].

Femoral angiography is the main line for the investigations in the peripheral occlusive arterial disease and in diagnosis of suspected congenital anomalies [3]. The anatomical knowledge of the level of origin of PFA is important in avoiding iatrogenic femoral arterio - venous fistula formed during puncture of femoral artery [4]. PFA is used for haemodialysis, vascular reconstructive procedures and various radio-imaging techniques like ultrasound Doppler imaging and MRI [5].

Hence, accurate knowledge of anatomical variations regarding origin of PFA, circumflex femoral arteries are very important for clinicians. Precise anatomy of PFA forms strong foundation to minimize complications.

\section{MATERIALS AND METHODS}

The present study includes 25 properly embalmed and formalin fixed adult human cadavers used for routine dissection procedure for undergraduate and postgraduate students in the department of Anatomy, Kurnool Medical College, Kurnool. The study was done by dissection method as per Cunningham's manual of practical anatomy.

\section{RESULTS}

Table 1: Showing origin of profundafemoris artery from femoral artery (Male and Female distribution, right and left side distribution).

\begin{tabular}{|c|c|c|c|c|}
\hline $\begin{array}{c}\text { Site of origin from } \\
\text { femoral artery }\end{array}$ & $\begin{array}{c}\text { No. of limbs } \\
\text { (Rt. side) }\end{array}$ & $\begin{array}{c}\text { No. of limbs } \\
\text { (Lt. side) }\end{array}$ & $\begin{array}{c}\text { No. of limbs } \\
\text { (Bilateral) }\end{array}$ & $\begin{array}{c}\text { Percentage } \\
\text { frequency }\end{array}$ \\
\hline $\begin{array}{c}\text { Posterolateral } \\
\text { aspect }\end{array}$ & $3 \mathrm{M}, 2 \mathrm{~F}=5$ & $4 \mathrm{M}, 1 \mathrm{~F}=5$ & $12 \mathrm{M}, 3 \mathrm{~F}=15$ & $\begin{array}{c}\mathrm{M}-38 \% \\
\mathrm{~F}-12 \% \\
50 \%\end{array}$ \\
\hline Lateral aspect & $4 \mathrm{M}, 2 \mathrm{~F}=6$ & $5 \mathrm{M}, 5 \mathrm{~F}=10$ & $2 \mathrm{M}, 0 \mathrm{~F}=2$ & $\begin{array}{c}\mathrm{M}-22 \% \\
\mathrm{~F}-14 \% \\
36 \%\end{array}$ \\
\hline $\begin{array}{c}\text { Posteromedial } \\
\text { aspect }\end{array}$ & $2 \mathrm{M}, 1 \mathrm{~F}=3$ & $2 \mathrm{M}, 0 \mathrm{~F}=2$ & $0 \mathrm{M}, 1 \mathrm{~F}=1$ & $\begin{array}{c}\mathrm{M}-8 \% \\
\mathrm{~F}-4 \% \\
12 \%\end{array}$ \\
\hline High origin & $0 \mathrm{M}, 0 \mathrm{~F}=0$ & $0 \mathrm{M}, 1 \mathrm{~F}=1$ & $0 \mathrm{M}, 0 \mathrm{~F}=0$ & $\begin{array}{c}\mathrm{M}-0 \% \\
\mathrm{~F}-2 \% \\
2 \%\end{array}$ \\
\hline Total & 14 & 18 & 18 & $100 \%$ \\
\hline
\end{tabular}

In the present study, 50 lower limbs were dissected out of which 34 limbs were of male cadavers and 16 limbs were of female cadavers and were observed for the site of origin of profundafemoris artery (PFA).

Out of 50 limbs it was found that PFA originated from posterolateral aspect of femoral artery (Fig 1) in 25 limbs (50\%), from lateral aspect of femoral artery (Fig 2) in 18 limbs (36\%), from posteromedial aspect of femoral artery (Fig 3) in 6 limbs (12\%) and higher level of origin (Fig 4) was observed only in left limb of one (1) female cadaver $2 \%$ (Table 1 ).

Fig. 1: Showing origin of profundafemoris artery from posterolateral aspect of femoral artery - Right limb

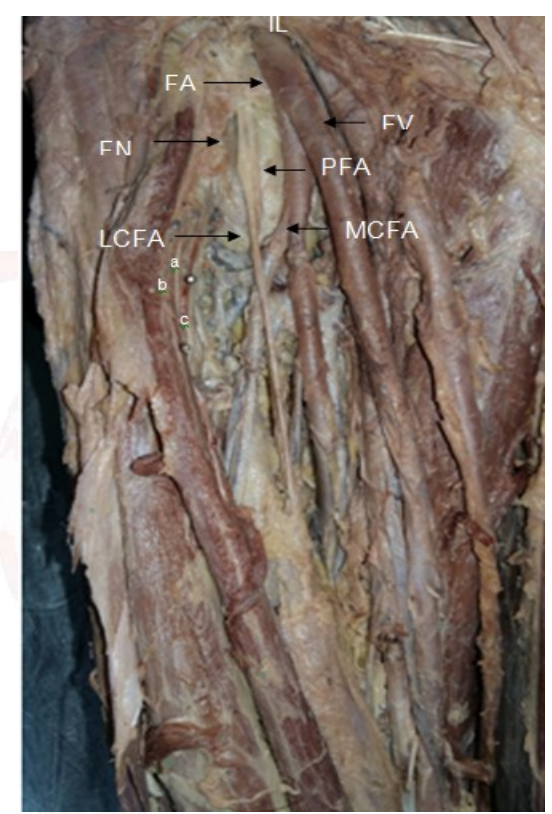

IL: Inguinal Ligament FA: Femoral Artery FV: Femoral Vein FN: Femoral Nerve PFA: Profundafemoris Artery MCFA: Medial Circumflex Femoral Artery LCFA: Lateral Circumflex Femoral Artery (a) - Ascending Branch b) - Transverse Branch(c) - Descending Branch Fig. 2: Showing origin of profundafemoris artery from lateral aspect of femoral artery - Right limb.

FA: Femoral Artery FV: Femoral Vein FN: Femoral Nerve PFA:Profundafemoris Artery MCFA:Medial Circumflex Femoral Artery LCFA: Lateral Circumflex Femoral Artery

a) - Ascending Branch b) - Transverse Branch C) - Descending Branch

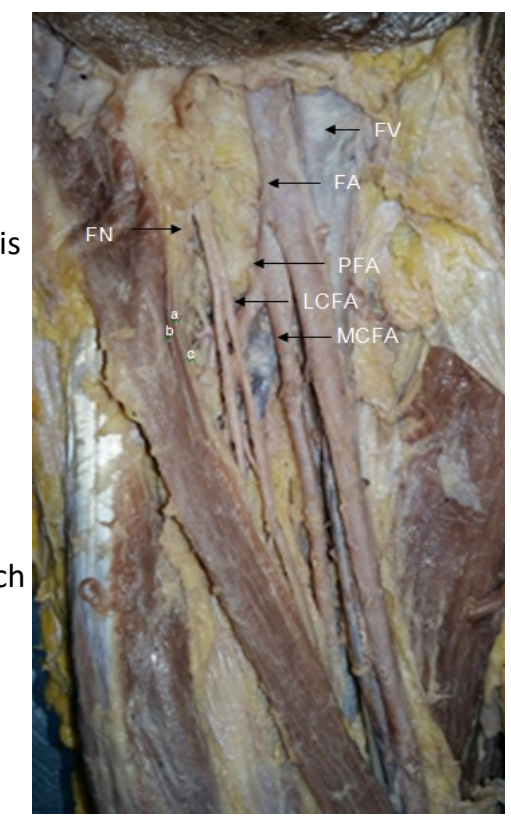


Fig. 3: Showing origin of profundafemoris artery from posteromedial aspect of femoral artery.

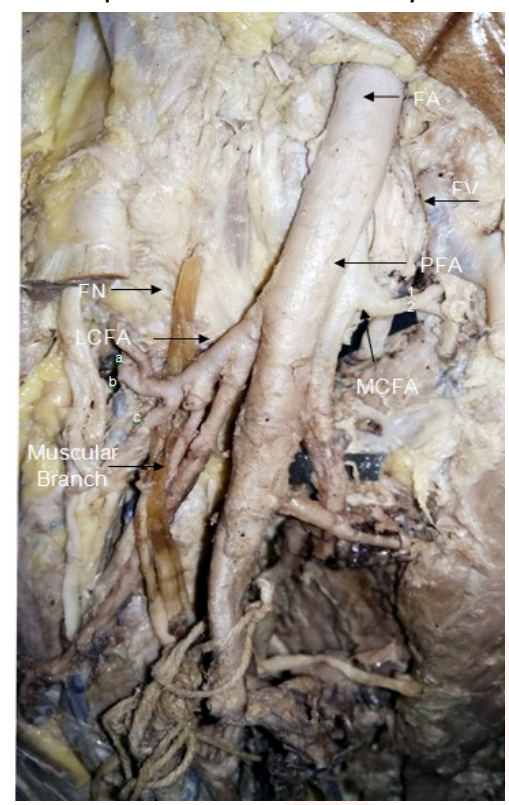

FA: Femoral Artery FV: Femoral Vein FN: Femoral Nerve PFA: Profundafemoris Artery MCFA: Medial Circumflex Femoral Artery 1) Ascending Branch 2) Transverse Branch LCFA: Lateral Circumflex Femoral Artery (a) - Ascending Branchb) - Transverse Branch c) - Descending Branch Fig. 4: Showing high origin of profundafemoris artery just below inguinal ligament - Left limb.

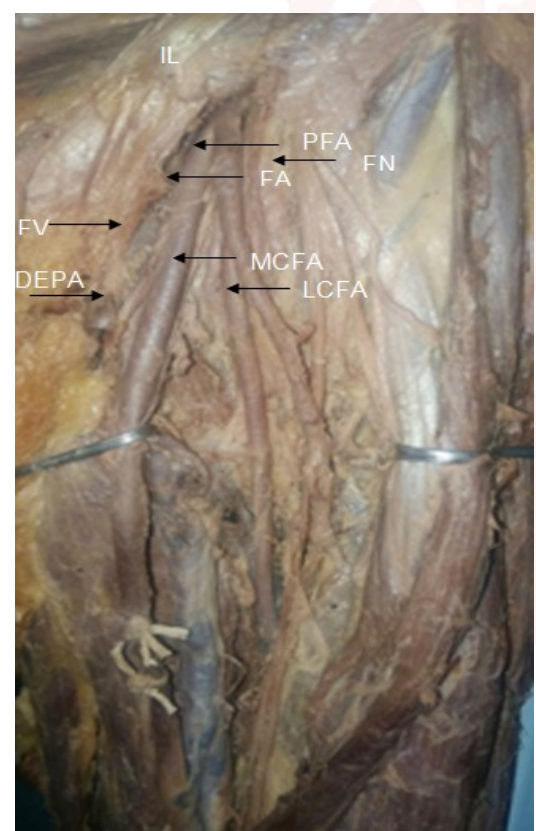

IL: Inguinal Ligament FA: Femoral Artery FV: Femoral Vein FN: Femoral Nerve PFA: Profundafemoris Artery MCFA: Medial Circumflex Femoral Artery LCFA: Lateral Circumflex Femoral Artery DEPA: Deep External Pudendal Artery

\section{DISCUSSION}

Variations may not endanger the life of patients and they are usually subclinical, but knowledge of variation in the origin of PFA and its branches is of great significance for preventing flap necrosis, particularly tensor fasciae latae, when used in plastic and reconstructive surgery and also important for the vascular surgeons and interventional radiologists ${ }^{(4,6)}$. This knowledge is also essential in the surgical repair of femoral hernias in vascular reconstructive procedures in the proximal leg. Plastic surgeons use the muscular branches while incorporating myocutaneous flaps. This vessel is useful for the Doppler imaging ultrasonography, arteriography and angiography and MRI $[5,7]$.

The knowledge of the site of origin of PFA is important while performing clinical procedures in the femoral region and in hip joint replacement and also for avoiding iatrogenic arterio venous fistula or severe secondary haemorrhage while performing femoral artery puncture [8]. The different anatomical relationships and lack of knowledge of variations of these vessels make the haemostasis difficult to manage [3].

In developmental process, some of the channels regress and some of them enlarge and form a definitive arterial pattern. The persistence of the channel that was supposed to disappear lead to various anomalies [6].

Sangeeta Jitendra Rajani et al [9] found that most common site of origin is posterolateral in $53.03 \%$, Prakash et al found that most common site of origin is posterolateral in $50 \%$, study conducted by Vaibhav et al [10] found that $47.5 \%$ is posterolateral, Brijesh R. Aghera et al [11] found that most common site of origin is posterolateral in $46.7 \%$. In present study most common site of origin of PFA is posterolateral in $50 \%$. Hence the present study correlates with the previous studies.

Samara Wikrama et al [12] found that lateral aspect origin of PFA from FA is $23 \%$, Siriporn T [13]. found that lateral aspect origin of PFA from FA is $21.4 \%$, Brijesh R. Agheraetal found that lateral aspect origin of PFA from FA is $19.6 \%$. In present study lateral aspect origin of PFA from FA is $36 \%$. Hence the present study does not correlate with the previous studies. Site of the origin of PFA from postereomedial aspect from FA is $13.63 \%$ by Sangeeta Jitendra Rajani et al; $10.78 \%$ observed by Brijesh R. Aghera et al; $10.5 \%$ observed by Daksha Dixit [14] and 12\% was observed in present study, conclude that 
Table 2: Comparison of site of origin of profundafemoris with other studies

\begin{tabular}{|c|c|c|c|c|c|c|c|c|}
\hline \multirow{2}{*}{$\begin{array}{c}\text { Site of origin from } \\
\text { Femoral Artery }\end{array}$} & \multicolumn{9}{|c|}{$\begin{array}{c}\text { Incidence } \\
\text { Study }\end{array}$} & $\begin{array}{c}\text { Prakash et al } \\
2010\end{array}$ & $\begin{array}{c}\text { Vaibhav et al } \\
2014\end{array}$ & $\begin{array}{c}\text { Brijesh R Aghera et al } \\
2015\end{array}$ & $\begin{array}{c}\text { Sangeetalitendr } \\
\text { aRajani et al } \\
2015\end{array}$ & $\begin{array}{c}\text { Dixit et al } \\
2011\end{array}$ & $\begin{array}{c}\text { Samara } \\
\text { Wikrama et al } \\
2009\end{array}$ & $\begin{array}{c}\text { Siripom T } \\
2012\end{array}$ \\
\hline Posterolateral & $50 \%$ & $50 \%$ & $47.50 \%$ & $46.70 \%$ & $53.03 \%$ & $35.14 \%$ & $30 \%$ & $30.36 \%$ \\
\hline Lateral & $36 \%$ & - & $16.66 \%$ & $19.60 \%$ & $18.17 \%$ & - & $23 \%$ & $21.43 \%$ \\
\hline Posteromedial & $12 \%$ & $3.10 \%$ & $14.16 \%$ & $10.78 \%$ & $13.63 \%$ & $10.50 \%$ & - & $3.57 \%$ \\
\hline High origin & $2 \%$ & - & - & - & $10 \%$ & - & - & - \\
\hline
\end{tabular}

postereo medial side of origin is less common but most dangerous because of presence of femoral vein.

In present study, incidence of high origin of PFA is $2 \%$; According to the study conducted by Sangeeta Jitendra Rajani et al observed that unilateral high origin was $10 \%$ and bilateral high origin of PFA $21.2 \%$ was observed (Table 2).

Anatomical variations found at the level of the division of the femoral artery and profundafemoris artery can be explained in the lower animals. "The profundafemoris artery is a branch of internal iliac artery". At the time of evolution, the origin shifted distally from the femoral artery. Hence, developmental arrest at different stages may lead to anatomical variations related to the division of femoral artery. From all the above discussions, we conclude that knowledge of various variations is very crucial during catheterization of FA and surgeries in femoral region to prevent severe hemorrhagic effect [10].

\section{CONCLUSION}

In the present study, we found that posterolateral side was the common site of origin of PFA followed by lateral side and posteromedial side. High level of origin of PFA was observed rarely.The knowledge of variations will help the clinicians to avoid iatrogenic complications and also help them in various clinical procedures and surgeries in femoral region.

\section{ABBREVIATIONS}

PFA - Profundafemoris Artery

FA - Femoral Artery

LCF - Lateral Circumflex Femoral Artery

MCF - Medial Circumflex Femoral Artery

IL - Inguinal Ligament

M - Male

F - Female
Conflicts of Interests: None

\section{REFERENCES}

[1]. Standring S. Pelvic girdle, Gluteal region and thigh, in: Gray's Anatomy, The anatomical basis of clinical practice. $40^{\text {th }} \mathrm{Ed}$.

[2]. Hollinshead HW. Textbook of Anatomy. 3rd Ed. Hagerstown, Maryland: Harper \& Row; 1974. p. 407.

[3]. Baptist M, Sultana F, Hussain T. The origin of profunda femoris artery, its branches and diameter of the femoral artery. Professional Med J. 2007; 14:523-27.

[4]. Prakash KJ, Kumar BA, Jose BA, Yadav Kumar S, Singh $G$. Variations in the origins of the profunda femoris and the medial and the lateral femoral circumflex arteries: a cadaver study in the Indian population. Rom J Morphol Embryol. 2010;51(1):167-70.[PubMed]

[5]. Phalgunan V, Srinivasan B. Variation of lateral circumflex femoral artery and profunda femoris artery:a case report. International journal of anatomical variations. 2013; 6:213-15.

[6]. Shetty AS, Shetty S, Rakesh G, Narendra P, Raghu J. An atypical outsized lateral circumflex femoral artery and its clinical implications. JCDR. 2012;6(7):1284-45.

[7]. Chitra R. A rare variational anatomy of the profunda femoris artery. Folia Morphol (Warsz) 2008; 67(2):157-58. [PubMed]

[8]. Dimri P, Deshwal AK. Bilateral high origin of profunda femoris artery-case report and embreological review. International journal of scientific research. 2014;3(1):375-76.

[9]. Sangeeta Jitendra Rajani et al cadaveric study of profundafemoris artery - Journal of clinical and diagnostic research 2015 (Vol.9 (5) - ACO1 - ACO3.

[10].Vaibhav Prakash Anjankar, Pradnyesh N. Panshewdikar, Gourav Thakre. Morphological study on branching pattern of Femoral artery: A Cadaveric study. Asia journal of Bio and Pharm Sci. 2014; 4:34-38.

[11]. Brijesh R. Aghera et al morphological study of origin of profundafemoris artery in human cadavers international Journal of Anatomy and Research 2015, Vol. 3.

[12].M B Samara Wikrama, BG Nanayakkara, KWR Wimalagunarathna, DG Nishantha. Branching pattern of the femoral artery at the femoral triangle: a cadaveric study. Galle Medi J 2009; 14:31-34. 
[13].Siriporn Thitilertdecha, T Rungruang, C Voraphattropas. The origin of profundafemoris artery in Thais, Siriraj Med J 2012; 64:34-36.

[14]. Dixit D, Dharati M. |Kubavat, Sureshbhai P. Rathod, Mital M. Patel, Tulsibhai C. Singel. Study of variation in origin of profundafemoris artery and its circumflex branches, Int J Biol Med Res 2011; 2:108489.

How to cite this article:

U. Sujatha, Prashanti T, K. Chitty Narasamma, Ch. Jayamma. STUDY OF VARIATIONS IN THE ORIGIN OF PROFUNDA FEMORIS ARTERY IN ADULT HUMAN CADAVERS. Int J Anat Res 2019;7(1.2):6187-6191. DOI: 10.16965/ijar.2018.439 